\title{
Development of Doubly Salient Permanent Magnet Motor Flywheel Energy Storage for Building Integrated Photovoltaic System
}

\author{
H.P. Kan, K.T. Chau and M. Cheng \\ Department of Electrical and Electronic Engineering, The University of Hong Kong
}

\begin{abstract}
With ever increasing concerns on environmental protection, the full utilization of inexhaustible solar energy is highly desirable. In this paper, a new energy storage system is proposed which consists of a building integrated photovoltaic (BIPV) array, a DC-DC converter, a doubly salient permanent magnet (DSPM) motor drive incorporated with a high-speed flywheel, and an inverter. It has the advantages that the BIPV array is practically feasible in modern cities, while the DSPM motor flywheel offers high efficiency, long cycle life and environmental friendliness.
\end{abstract}

\section{INTRODUCTION}

With ever increasing concerns on our environment, the full utilization of inexhaustible solar energy and the development of environment-friendly energy storage are key issues. The purpose of this paper is to simultaneously address these two issues, namely the development of a new electromechanical energy storage system for a modern photovoltaic system. Firstly, the full utilization of solar energy is achieved by establishing a building integrated photovoltaic (BIPV) system with the use of maximum power point tracking (MPPT) technique. This BIPV array is particularly useful in modern cities in which there are numerous high-rise buildings. Secondly, the environment-friendly energy storage is achieved by developing a new doubly salient permanent magnet (DSPM) motor drive [1]-[3] with a high-speed flywheel. This DSPM motor flywheel system takes definite advantages over the conventional battery storage in terms of efficiency, cycle life and environmental friendliness. Moreover, the proposed BIPV-DSPM-flywheel system can serve as an uninterruptible power system or a distributed power system in those high-rise buildings in modern cities.

\section{BIPV SYSTEM IN MODERN CITIES}

According to the meteorological data record in 1999 obtained from the Hong Kong Observatory, the potential of applying BIPV technology in modern cities like Hong Kong is promising. Fig. 1 shows the corresponding monthly total bright sunshine duration. Hence the Solar radiation on the tilted surface can be calculated from the meteorological data [4]. Fig. 2 shows the mean daily global solar radiation in Hong Kong on a horizontal surface and an equator-facing vertical surface. The mean electricity generation capacity in unit area of the PV array on the vertical wall is $43.6 \%$ of that on the horizontal surface. In high population density of commercial cites like Hong Kong, most buildings are high-rise construction. The BIPV system can utilize the large surface area of the walls for PV modules, which have significant contribution to the total PV electricity generation.

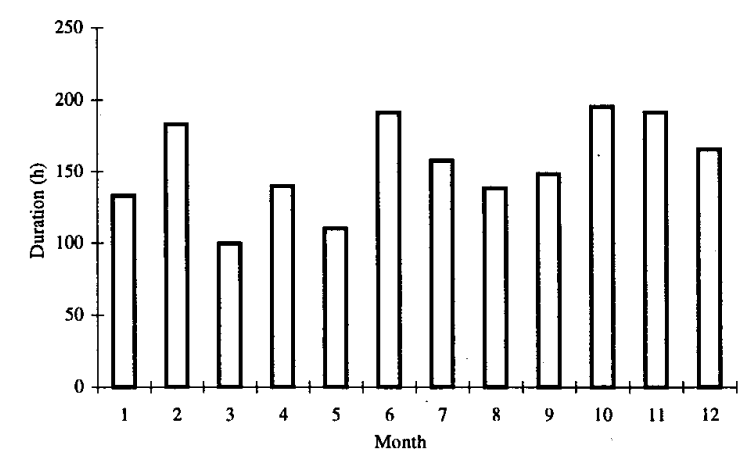

Fig. 1. Monthly total bright sunshine duration

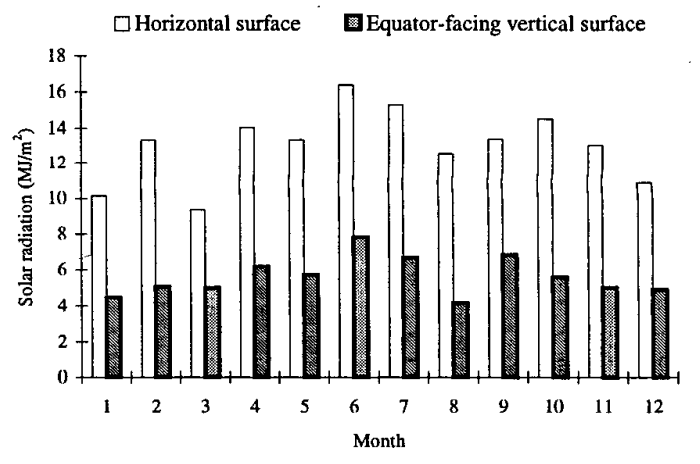

Fig. 2. Mean daily global solar radiation

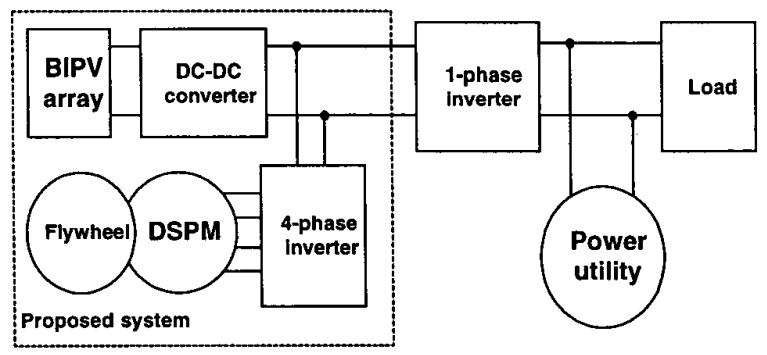

Fig. 3. Proposed BIPV-DSPM-flywheel system. 

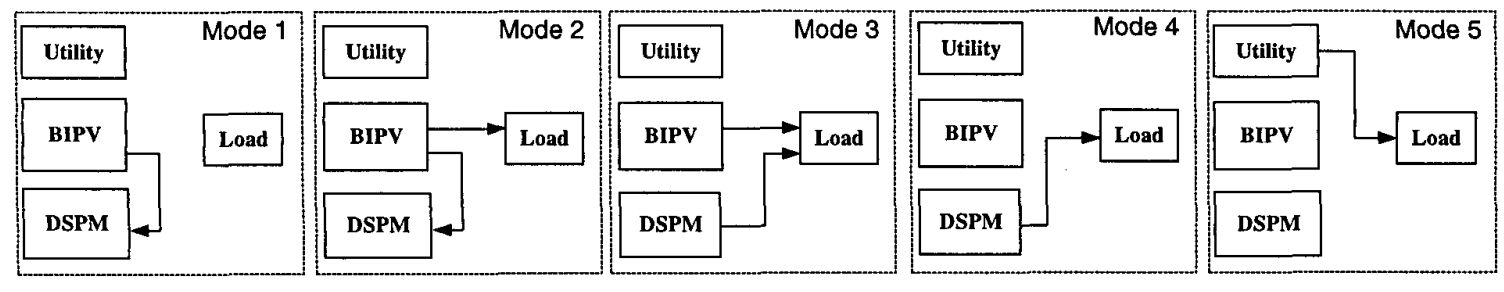

Fig. 4. Modes of operation.
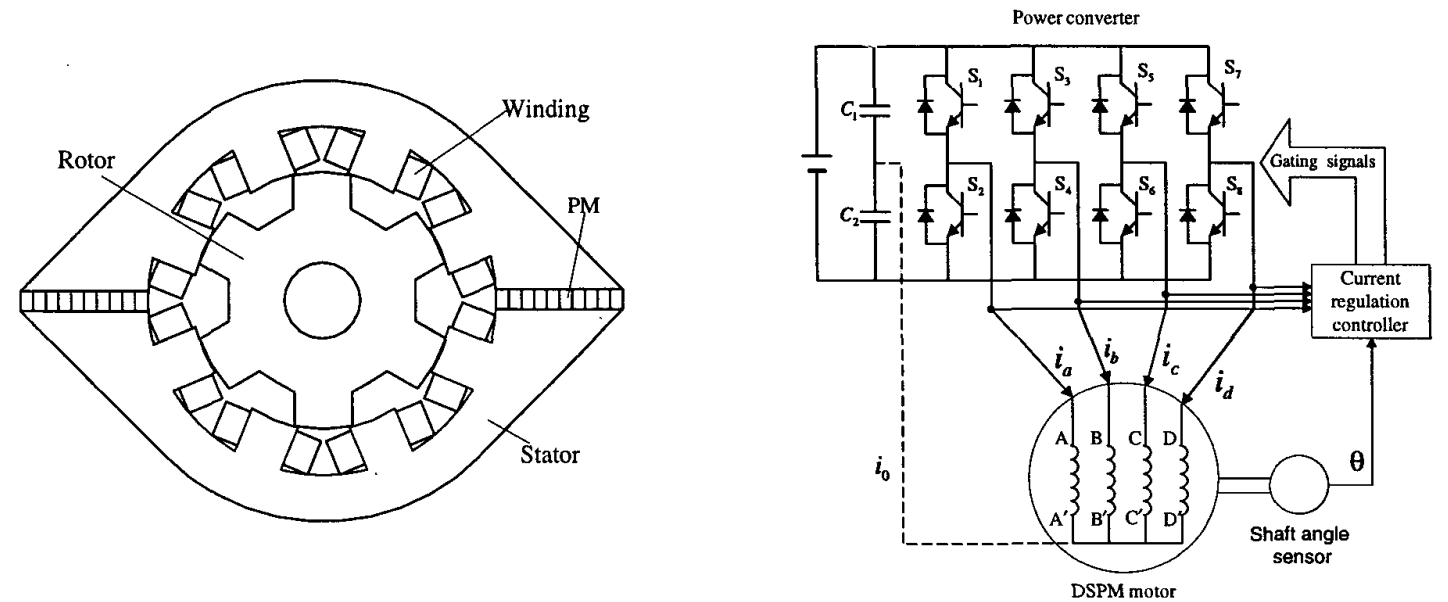

Fig. 5. Proposed DSPM motor drive.
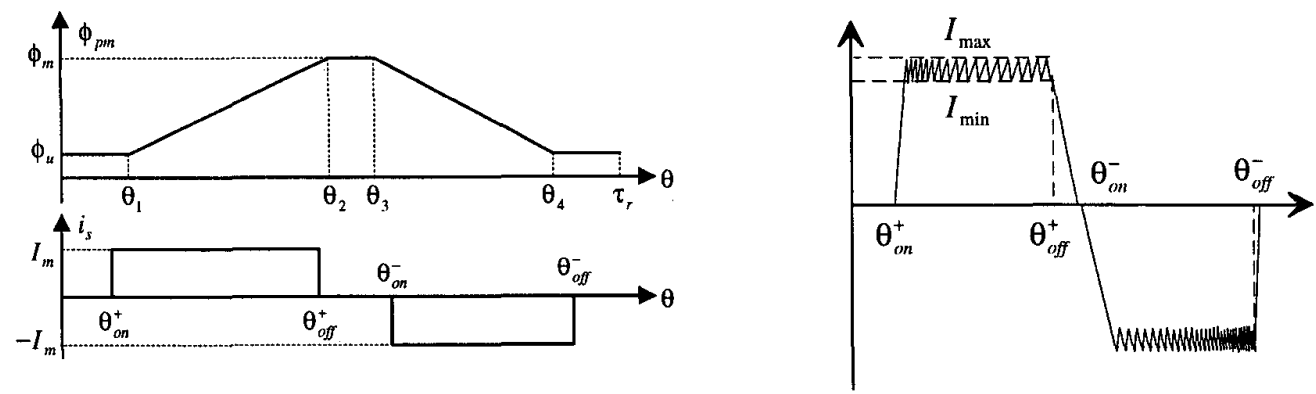

Fig. 6. Operating waveforms.

\section{SYSTEM DESCRIPTION}

Fig. 3 shows the proposed BIPV-DSPM flywheel system. It consists of a BIPV array, a DC-DC converter, a 4-phase inverter, a DSPM motor and a high-speed flywheel. According to the possible power flow conditions among these system components, there are 5 modes of operation as shown in Fig.4:

- Off-Load Period (Mode 1): no load is required by the building and all energy generated by the BIPV is stored in the DSPM flywheel.

- High-Insolation Period (Mode 2): the BIPV energy is greater than the load and the surplus is stored in the DSPM flywheel.

- Low-Insolation Period (Mode 3): the BIPV energy is less than the load and the DSPM flywheel supplements the necessary energy to match the load.

- Discharging Period (Mode 4): no BIPV energy is generated and the DSPM flywheel supplies the load until fully discharged.

- Utility Period (Mode 5): since the BIPV energy is below the threshold and the DSPM flywheel energy is exhausted, the utility takes action. 


\section{DSPM MOTOR DRIVE}

Fig. 5 shows the proposed DSPM motor drive for flywheel energy storage. This 4-phase 8/6-pole DSPM motor essentially adopts the same structure as a switched reluctance motor, but with PMs placed in the stator. Since there are neither PMs nor windings in the rotor, the machine is free of maintenance and capable of ultrahighspeed operation. Since the stator adopts concentrated windings, the overhanging part is very short, resulting in reduction of copper loss.

Assuming the fringing offset is negligible, and the permeability of the core is infinite, a linear variation of PM flux linkage is produced in each of stator windings at no-load. The principle of operation is illustrated by the waveforms shown in Fig. 6.

The voltages at the terminal of the DSPM motor can be described as: $\bar{U}=\bar{R} \bar{I}+d \bar{\Psi} / d t$ where $\bar{U}$ is the voltage matrix, $\bar{R}$ is the resistance matrix, $\bar{I}$ is the current matrix, and $\bar{\Psi}=\bar{L} \bar{I}+\bar{\Psi}_{m}$ is the flux linkage matrix. When both of $\bar{L}$ and $\bar{\Psi}_{m}$ are considered to be spatially dependent only and independent of the stator current, it yields

$$
\begin{gathered}
\frac{d \bar{\Psi}}{d t}=\bar{L} \frac{d \bar{I}}{d t}+\frac{d \bar{L}}{d t} \bar{I}+\frac{d \bar{\Psi}_{m}}{d t}, \\
\frac{d \bar{\Psi}}{d t}=\bar{L} \frac{d \bar{I}}{d t}+\frac{d \bar{L}}{d \theta} \bar{I} \omega_{r}+\frac{d \bar{\Psi}_{m}}{d \theta} \omega_{r},
\end{gathered}
$$

where $\omega_{r}$ is the angular velocity of the motor, and $\theta$ is the rotor position angle defined as the angle between the central lines of stator pole and rotor slot. Thus, the dynamic equation (1) can be rewritten as

$$
\frac{d \bar{I}}{d t}=-\bar{L}^{-1}\left[\bar{R}+\frac{d \bar{L}}{d \theta} \omega_{r}\right] \bar{I}+\bar{L}^{-1}\left[\bar{U}-\frac{d \bar{\Psi}_{m}}{d \theta} \omega_{r}\right],
$$

By employing the co-energy method, the torque equation of the motor can be derived as

$$
\begin{gathered}
T_{e}=\frac{\partial W^{\prime}}{\partial \theta}=\frac{\partial}{\partial \theta}\left[\frac{1}{2} \bar{I}^{T} \bar{L}_{\bar{I}}+\bar{\Psi}_{m}^{T} \bar{I}\right], \\
T_{e}=\frac{1}{2} \bar{I}^{T}\left(\frac{\partial}{\partial \theta} \bar{L}\right) \bar{I}+\left(\frac{\partial}{\partial \theta} \bar{\Psi}_{m}\right)^{T} \bar{I}=T_{r}+T_{p m},
\end{gathered}
$$

where $T_{e}$ is the total electromagnetic torque, $T_{r}$ represents the reluctance torque component due to the variation of inductances, and $T_{p m}$ is the PM torque component due to the interaction between the winding current and PM flux. Hence, the motion equation of the DSPM motor flywheel is given by

$$
\frac{d \omega_{r}}{d t}=\frac{1}{J}\left(T_{e}-T_{l}-B_{v} \omega_{r}\right),
$$

where $T_{l}$ is the load torque, $B_{v}$ the viscous-damping coefficient, and $J$ the moment of inertia.

\section{TABLE I}

Composite materials for ultrahigh-speed flywheels

\begin{tabular}{|c|c|c|c|}
\hline Material & $\begin{array}{c}\text { Tensile } \\
\text { Strength } \sigma \\
(\mathbf{M P a})\end{array}$ & $\begin{array}{c}\text { Specific } \\
\text { Density } \rho \\
\left(\mathbf{k g} / \mathbf{m}^{3}\right)\end{array}$ & $\begin{array}{c}\text { Ratio } \sigma / \rho \\
(\mathbf{W h} / \mathbf{k g})\end{array}$ \\
\hline S-glass & 2069 & 1900 & 303 \\
\hline $\begin{array}{c}\text { Kevlar } \\
\text { epoxy }\end{array}$ & 1930 & 1400 & 383 \\
\hline $\begin{array}{c}\text { Graphite } \\
\text { epoxy }\end{array}$ & 1586 & 1500 & 294 \\
\hline E-glass & 1379 & 1900 & 202 \\
\hline
\end{tabular}

\section{FLYWHEEL}

Flywheel stores mechanical energy in kinetic form as given by

$$
W_{K E}=\frac{1}{2} J \omega_{r}{ }^{2}
$$

where $J$ and $\omega$ are the inertia and the angular velocity of the flywheel. $\mathrm{J}$ is depends on the structure of the flywheel system design. Therefore, the energy storage is proportional to the square of $\omega$ and the storage capacity is limited by the maximum angular velocity $\omega_{\max }$, which is governed by the specific strength of the materials used. For selection of flywheel materials, Table 1 summarizes the theoretical limit based on differing composite materials.

Flywheel energy storage offers the following advantages over conventional batteries:

(i) Environmental friendly, particularly of disposal.

(ii) Life long up to 20 years, which is comparable to that of PV array.

(iii) Very high charging and discharging rate.

(iv) Able to cyclic discharged to zero energy without degrading whatsoever.

(v) Operation independent to temperature fluctuations.

\section{PHOTOVOLTAIC CELL}

A photovoltaic (PV) cell is a large-area pn-junction (diode) forward bias with a photovoltage and structure designed for efficient conversion of sunlight into electric current. The photovoltage is created from the dissociation of electron hole pairs created by incident photons within the build-in field of the junction.

The I-V characteristics of the PV cell can be described by

$$
V_{c e l l}=\frac{K T}{q} \ln \left(\frac{I_{s c}-I_{c e l l}}{I_{o}}+1\right) \text {, }
$$



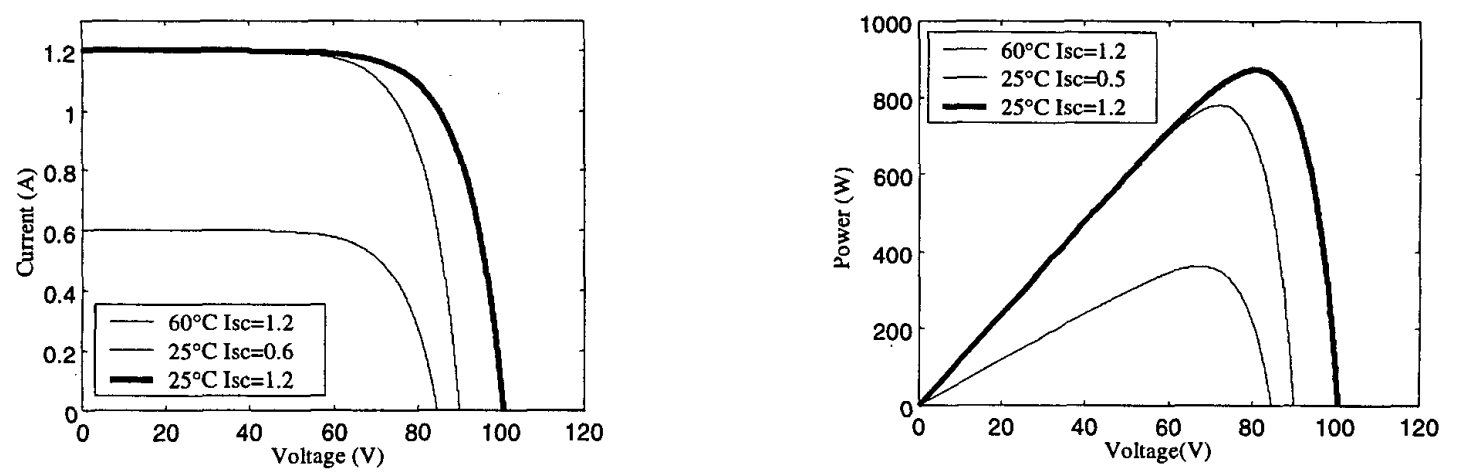

Fig. 7. Characteristics of PV array.

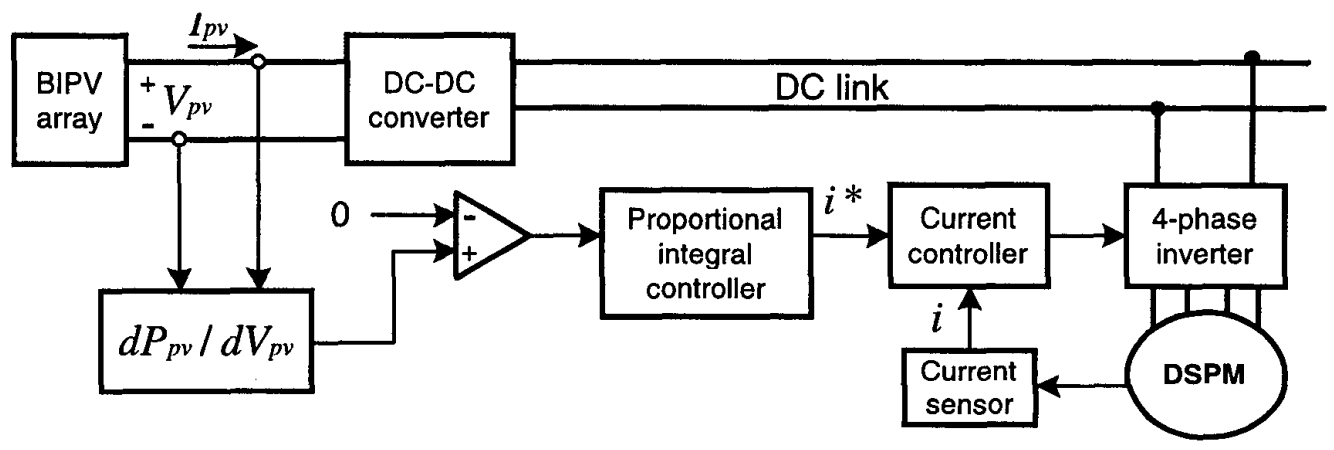

Fig. 8. Proposed MPPT by DSPM motor control.

where $V_{c e l l}$ and $I_{c e l l}$ are respectively the operating voltage and current, $K$ the Boltzmann constant, $T$ the absolute temperature, $I_{s c}$ the short circuit current, and $I_{o}$ the saturation current. The operating voltage and current of the PV array are $V_{\text {array }}=N_{s} V_{\text {cell }}$ and $I_{\text {array }}=N_{p} I_{\text {cell }}$ where $N_{s}$ and $N_{p}$ are respectively the number of series and parallel cells. Thus, the characteristics of the PV array are simulated and shown in Fig. 7.

The P-V and I-V characteristics are important properties for the design of MPPT. The maximum power point occurs at which the slope $d P_{P V} / d V_{P V}$ is zero. In order to achieve the maximum power operating point, the PV array output current $I_{P V}$ is controlled in such a way that it decreases at a positive slope of $d P_{P V} / d V_{P V}$ and increases at a negative slope of $d P_{P V} / d V_{P V}$. Conventional MPPT controller is done by current-mode control of the DC-DC converter, where the boost chopper stage is used to maximize the PV array output power by adjusting its duty ratio [5].
For the proposed system, the MPPT is achieved by a new way. As shown in Fig. 8, the DSPM motor current $I_{D S P M}$ is so controlled that $I_{P V}$ is tuned to attain the MPPT.

\section{SIMULATION OF MPPT CONTROL}

Computer simulations are carried out to confirm the performance of the proposed MPPT control technique. The I-V characteristic of the PV array is described by (8). By changing the short-circuit current and temperature, various operating conditions can be set.

Fig. 9 shows the simulated results of the MPPT control for a step change of the insolation level. In Fig. 9(a), the system starts to track the maximum power from point "a". It keeps the operating point at point " $b$ " with a maximum power $600 \mathrm{~W}$. A step increase of insolation at point "c" activate the system which then pushes the operating point to " $\mathrm{d}$ " with a maximum power $1000 \mathrm{~W}$.

Similarly, Fig. 9(b) illustrates that the system works properly for a step decrease of insolation at point " $c$ " thus changing the maximum PV power from $1000 \mathrm{~W}$ to $800 \mathrm{~W}$. 

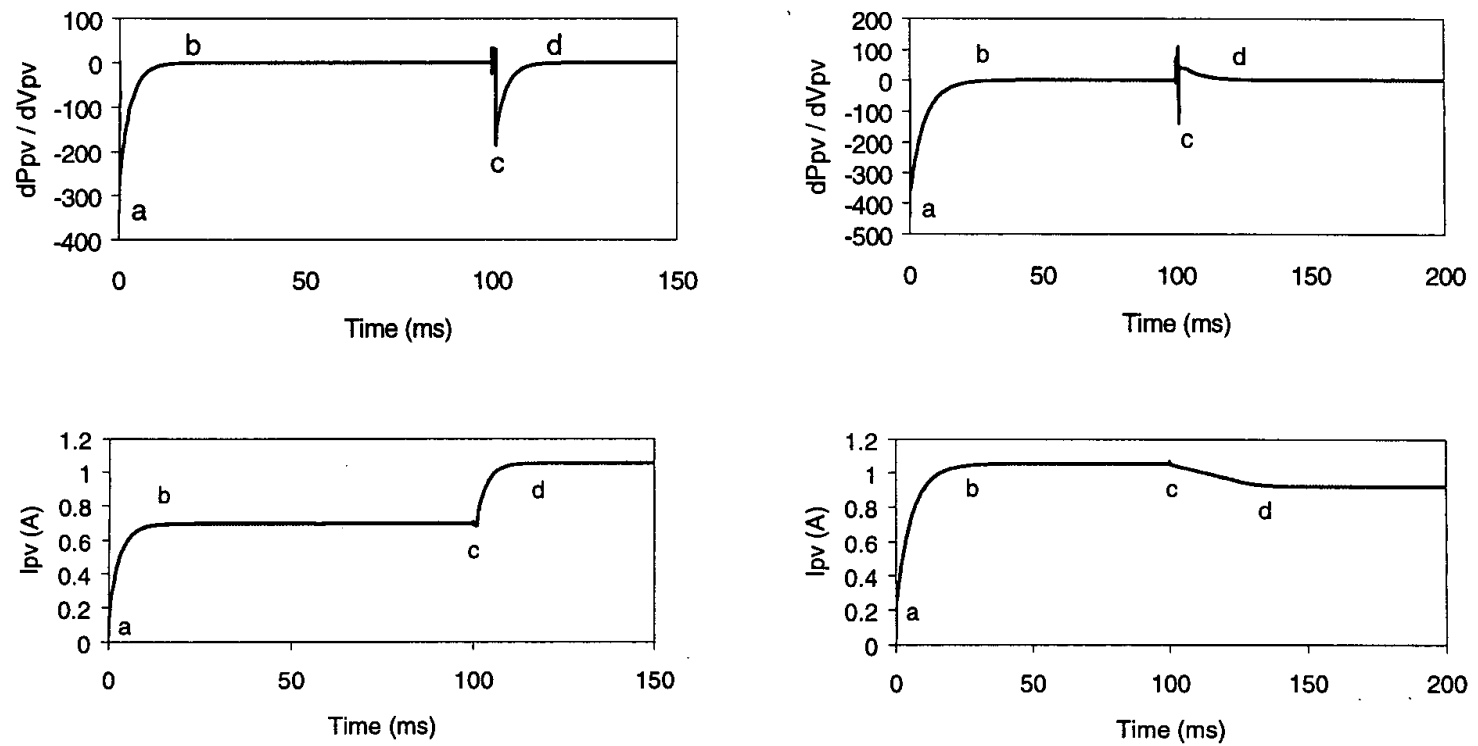

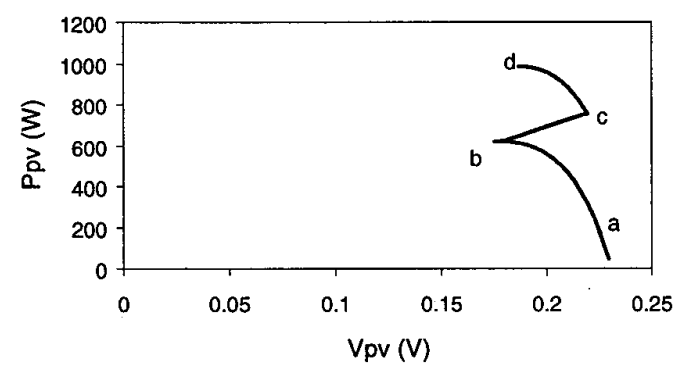

(a)

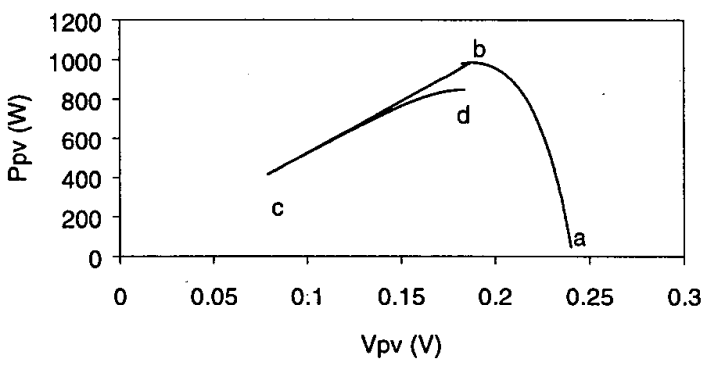

(b)

Fig. 9. Simulated results of MPPT control. (a) Step increase in insolation. (b) Step decrease in insolation.

\section{DC-DC CONVERTER}

The DC-DC converter in the system is a boost type used to step up the PV voltage to the level of the DC link of the system. The configuration of a basic boost converter is shown in Fig. 10. Assuming a lossless circuit, in steady state, $V_{\text {out }}=V_{\text {in }} /(1-D)$ and $I_{\text {out }}=I_{\text {in }}(1-D)$, where $D$ is the switch duty ratio defined as the ratio of the on duration to the switching period.

Based on the above mentioned MPPT scheme, the boost converter is normally not in charge for the MPPT when the PV power is above the load requirement and the duty ratio is for voltage boosting function only. Thus, complicated multi-loop current-mode control, which is usually employed for MPPT of PV systems, can be avoided. Actually, in this design, a simple voltage-mode control is used only. Fig. 11 shows the block diagram of its pulse width modulation (PWM) switching control.
However, whenever the PV power is not sufficient to supply the load, namely the current supplied to the DSPM flywheel becomes zero, the boost converter plays an important role to control and activate the generation mode of the DSPM flywheel. If the solar radiation decreases to a certain value that the output power exceeds the maximum power of the PV generation, the DC link voltage will quickly decay because the input and output power equilibrium at the DC link is no longer satisfied. However, the DSPM flywheel is connected in parallel to the DC link via a 4-phase inverter. When the DC link voltage is below the back EMF of the DSPM motor, the motor will automatically change from the motoring mode to the generation mode. Current from each phase of the motor will flow through the diodes and supply back to the DC link. As a result, the input and output power equilibrium is satisfied and the DC link voltage is kept equal to the back EMF of the DSPM motor. 


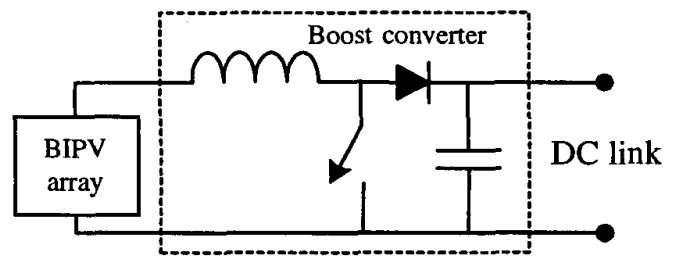

Fig. 10. DC-DC converter (boost type).

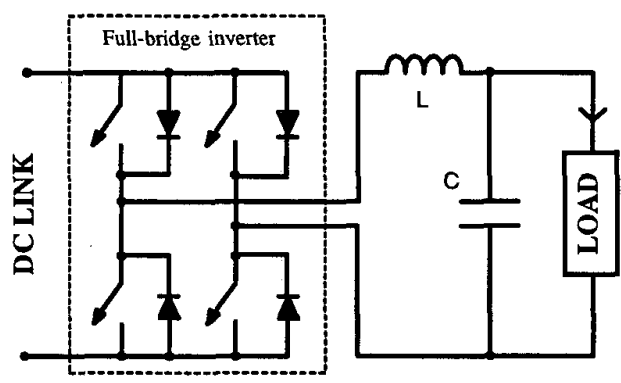

Fig. 12. Full-bridge inverter.

\section{INVERTER}

A basic full-bridge inverter is used in this system. The schematic diagram is shown in Fig. 12. Conventional PWM control method is being used as shown in Fig. 13.

Special matters are needed to concern for the inverter design when the BIPV system is interconnected with the utility. On 30 January 2000, IEEE-SA Standard Board approved "IEEE Recommended Practice for Utility Interface of Photovoltaic (PV) Systems" [6]. This recommended practice contain guidance regarding equipment and functions necessary to ensure compatible operation of PV systems that are connected in parallel with the power utility. This includes factors relating to personnel safety, equipment protection, power quality, and utility system operation. It also contains information regarding islanding of PV systems when the utility is not connected to control voltage and frequency, as well as techniques to avoid islanding of distributed resources.

\section{SYSTEM SIMULATION}

A high-rise commercial building in Hong Kong is used to exemplify the proposed system. The corresponding computer simulation results are shown in Fig. 14. It can be found that the BIPV power behaves like a half-cycle sinusoid superimposed with perturbations, which is due to the real situation that the solar radiation varies with passing cloud or other environmental effects. The time scale starts from $6 \mathrm{am}$. The load power is due to a constant lighting load starting from 8am. The DSPM motor power is the difference between the BIPV power and the load. At point " $A$ ", the load suddenly changes from zero to $4 \mathrm{~kW}$ so

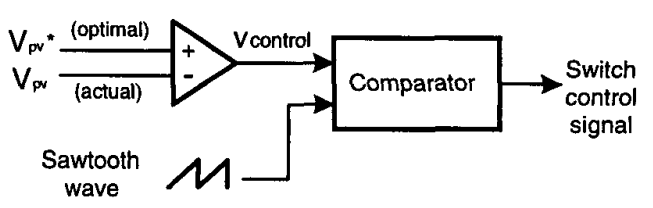

Fig. 11. PWM control for boost converter.

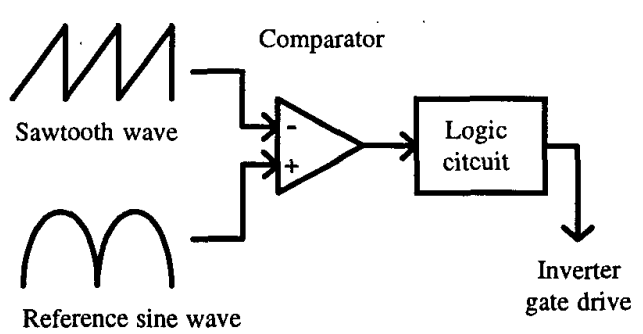

Fig. 13. PWM control for Inverter.

that the BIPV power is insufficient to satisfy the load and the DSPM motor flywheel serves as a generator to supply the necessary power to match the load. When the BIPV power continues to increase, the DSPM motor flywheel switches back to motoring to store kinetic energy. Similar situation occurs at point "B" where the BIPV power drops below the load. In the DSPM motor flywheel speed characteristic, the point " $C$ " corresponds to the point " $A$ " while the point " $\mathrm{D}$ " to the point " $\mathrm{B}$ ". Without the proposed energy storage system, the load can be supplied by the BIPV system only from around $9 \mathrm{am}$ to $3 \mathrm{pm}$. With the proposed system, the BIPV system can satisfy the load from $8 \mathrm{am}$ to beyond $6 \mathrm{pm}$, hence lengthening the time period by over $70 \%$.

\section{CONCLUSION}

This paper has newly proposed the DSPM motor flywheel energy storage for BIPV system, hence refraining from the use of those environmentally harmful batteries. The PV power makes the system flexible in power usage, so that all powers in the system can be utilized in a costeffective manner. The MPPT of the PV array is based on the power equilibrium in the DC link and controlled by the DSPM motor load. Simulation results done by MATLAB have been provided to demonstrate the operation and effectiveness of the proposed system.

\section{REFERENCE}

[1] Y. Liao, F. Liang and T.A. Lipo, "A novel permanent magnet motor with doubly salient structure," IEEE Trans. Ind. Appl., vol.31, 1995, pp. 1069-1078. 
[2] K.T. Chau, M. Cheng and C.C. Chan, "Performance analysis of 8/6-pole doubly salient permanent magnet motor," Electric Machines \& Power Systems, vol.27, 1999, pp. 1055-1067.

[3] M. Cheng, K.T. Chau, C.C. Chan. E. Zhou and X. Huang, "Nonlinear varying-network magnetic circuit analysis for DSPM motors," IEEE Trans. Mag., vol.36, 2000, pp. 339-348.

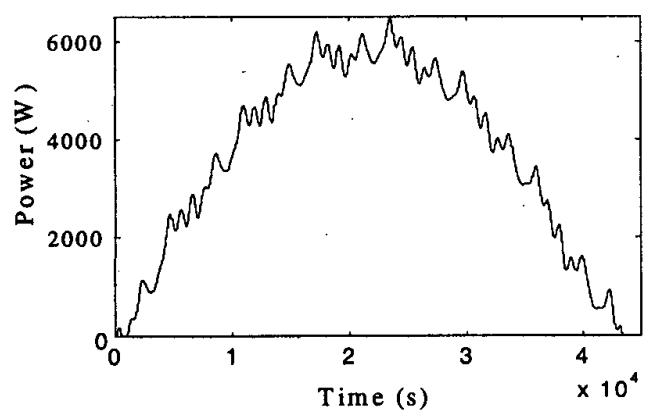

BIPV power

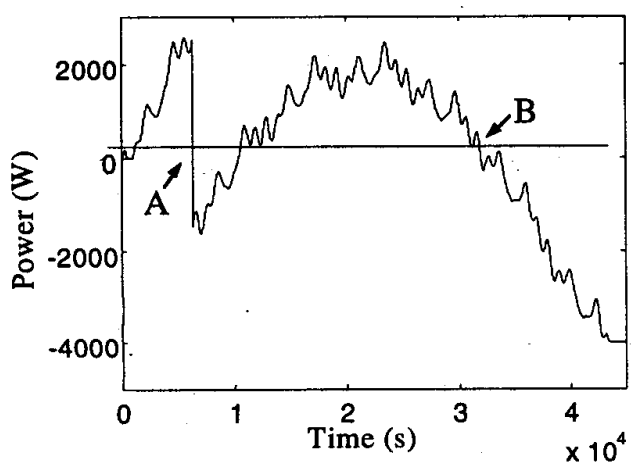

DSPM motor power

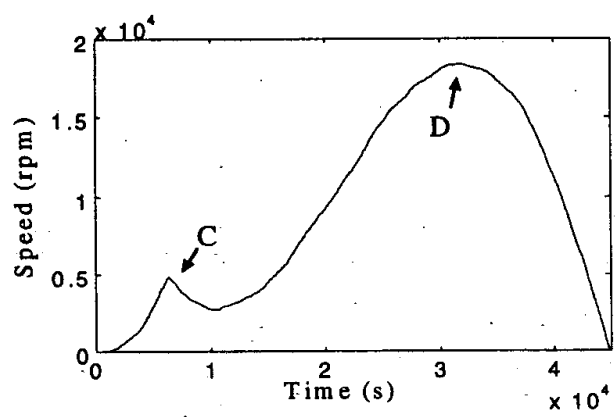

DSPM motor speed
4] T.A. Reddy, The Design and Sizing of Active Solar Thermal Systems, Oxford, 1987.

[5] S.J. Chiang, K.T. Chang, and C.Y. Yen, "Residential photovoltaic energy storage system," IEEE Trans. Ind. Elec., 1998, pp. 385-394.

[6] IEEE Recommended Practice for Utility Interface of Photovoltaic (PV) systems, 2000.

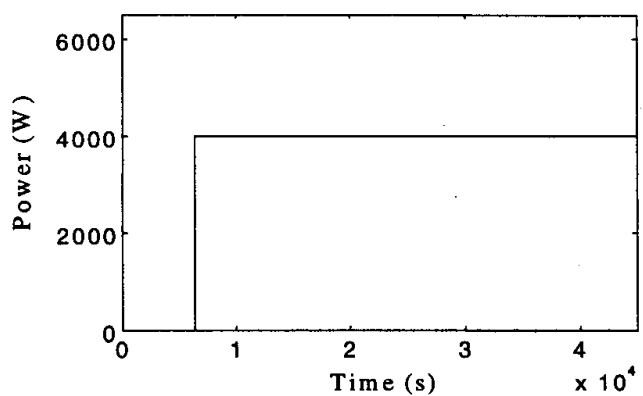

Load power

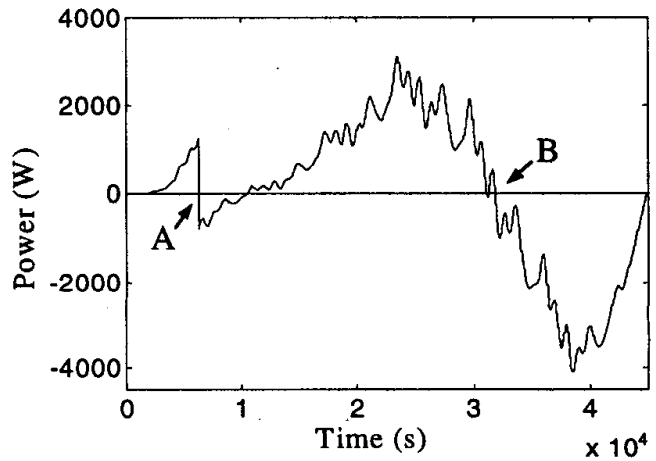

Flywheel power

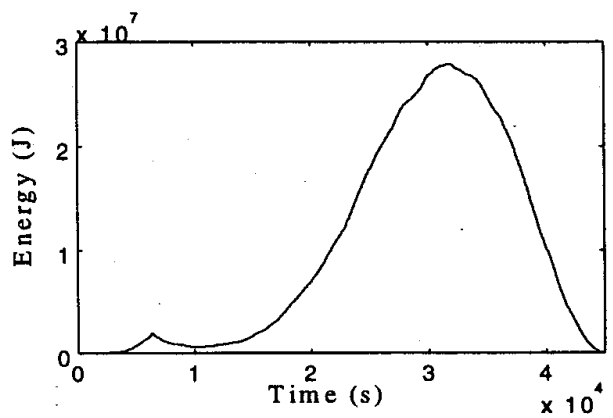

Flywheel energy

Fig. 14. Computer simulation result. 